\title{
Theoretic and Experimental Studies on the Casting of Large Die-Type Parts Made of Lamellar Graphite Grey Pig Irons by Using the Technology of Polystyrene Moulds Casting from Two Sprue Cups
}

\author{
Constantin Marta, Ioan Ruja, Cinca Ionel Lupinca, and Monica Rosu \\ Department of Engineering, University “Eftimie Murgu” of Resita, Piaţa Traian Vuia, nr.1-4, 320085 Resita, \\ Jud. Caras-Severin, Romania \\ Correspondence should be addressed to Constantin Marta, c.marta@uem.ro
}

Received 30 April 2012; Revised 30 August 2012; Accepted 13 September 2012

Academic Editor: Philippe Boisse

Copyright ( $\odot 2012$ Constantin Marta et al. This is an open access article distributed under the Creative Commons Attribution License, which permits unrestricted use, distribution, and reproduction in any medium, provided the original work is properly cited.

This paper presents a comparative analysis between the practical results of pig iron die-type part casting and the results reached by simulation. The insert was made of polystyrene, and the casting was downward vertical. As after the part casting and heat treatment cracks were observed in the part, it became necessary to locate and identify these fissures and to establish some measures for eliminating the casting defects and for locating them. The research method was the comparisons of defects identified through verifications, measurements, and metallographic analyses applied to the cast part with the results of some criteria specific to simulation after simulating the casting process. In order to verify the compatibility between reality and simulation, we then simulated the part casting respecting the real conditions in which it was cast. By visualising certain sections of the cast part during solidification, relevant details occur about the possible evolution of defects. The simulation software was AnyCasting, the measurements were done through nondestructive methods.

\section{Introduction}

The pearlitic grey pig irons constitute of family of ferrous materials with a wide range of mechanical properties, being using in the manufacture of bed frames, cylinder covers, dies, mechanisms bodies, pistons, cylinders [1]. The properties of strength, tenacity, and plasticity of the lamellar graphite pig irons are relatively low. These alloys exhibit unique proprieties of use due to the presence of graphite under the form of lamellas, such as: capacity of vibration damping, "lubricant" character; high processability; good resistance to abrasion; good corrosion resistance; preservation of properties in the temperature range from $-100^{\circ} \mathrm{C}$ to $+350^{\circ} \mathrm{C}$; very good resistance to heat shocks, very good castability. The parts are produced by casting in moulds, which makes them usable in the manufacture of mechanical components. Other advantages are the low cost and the wide scope of uses. The cooling rate of cast parts may affect the toughness and structure of the materials. In the present case we executed a die of lamellar graphite pig iron, toughness $>150<300$ $\mathrm{HB}$ mechanic strength $>500<1000 \mathrm{~N} \cdot \mathrm{mm}^{-2}$. This group of pig irons represents the quality of high strength generally obtained through a pearlitic die, which is relatively tough and has low tenacity and good processability. The casting of large die-type parts, approximately $11,000 \mathrm{~kg}$ raises a problem of the design and elaboration technology are not respected, especially the procedures of pig irons modification. The technology of casting in polystyrene moulds with two runner basins exhibits some particularities with major consequences on the parts quality.

\section{Analysis of the Cast Part}

Table 1 shows the chemical composition in \% weight $[1,2]$, as well as the execution of the part according to the own 
TABLE 1: Chemical compositon of material, (wt.\%).

\begin{tabular}{ccccccc}
\hline & $\mathrm{C}$ & $\mathrm{Si}$ & $\mathrm{Mn}$ & $\mathrm{P}$ & $\mathrm{S}$ & $\mathrm{Cu}$ \\
\hline EN GJL 200 & $3.15-3.45$ & $2.00-1.40$ & $0.60-0.80$ & $\max 0.200$ & $0.05-0.100$ & - \\
\hline
\end{tabular}

casting technology, specific to the casting in polystyrene moulds. The charge was cast through two runner basins.

After casting the visual verification of the cast surface and the location of possible casting defects were carried out. The defect in the cast part occurs under the form of a transversal crack in the median area of the part, on the horizontal base plate, 2 to $2.5 \mathrm{~mm}$ width and $1500 \mathrm{~mm}$ long, defect which appears in Figure 1. Figure 1 shows the areas where one has extracted the metallographic samples, marks: A, B, and F.

The analysis contains study of the design of the part geometry by visual analysis and extraction of metallurgic samples from the area of the defect. From the part design viewpoint, we find that the joining angle between ribs (fins) and the body of the part is $90^{\circ}$ without junctions, and the ribs have widths ranging between $25 \mathrm{~mm}$ and $90 \mathrm{~mm}$ without respecting the basic principles of the casting moulds $[3,4]$.

\section{Macro- and Microstructural Analysis}

According to Figure 1, three samples were extracted from three different zones: (1) F-position middle zone where the crack occurred, (2) final zone A, and (3) end zone B.

3.1. Macro- and Microstructural Analysis of Area F. Figure 2 shows the sample extracted from area $F$, that is, the middle area of the part where the crack occurs. This area is where the two metal fronts merged. The casting was done by using two sprue cups placed at the ends of the casting mould.

Figure 2 presents the middle area, that is, the zone where the crack occurs and at the same time the joining zone of the two jets (flowing currents) of the liquid pig iron. This zone exhibits nonmetallic inclusions such as oxides, sulphides, and small gaseous inclusions (air bubbles) which may constitute crack triggers in the conditions of the existence of very high internal strains generated by a braked contraction during solidification and cooling. One should remark the area of primary graphitisation in the insufficiently developed eutectic cells, due to the low casting temperature $\left(1220^{\circ} \mathrm{C}\right)$, and to a accelerated rate cooling area, as well as to a weak modification of the pig iron. By exceeding the time between modification and casting by over 15 minutes, the effect of the modification is very much attenuated [4]. There occur also air bubbles and oxides, as the middle area is the joining zone of the jets of liquid alloy come from the two sprue cups. Due to the fact that the part casting was made with two sprue cups we encounter two liquid fronts with different temperatures (of which one has the temperature below the technological casting level), as well as the differences in chemical composition. All these factors are potentially probabilistically generators of the defects from the above macroscopic image. The area where the defect is not oxidised which shows that the crack occurred at cold.

In Figure 3 one observed a microstructure of hypereutectic grey pig with metallic mass of pearlitic base, according to the chemical composition analysed, confirms the weak evolution of the separation of primary graphite, in the process of passing through the solidification range. Obviously the casting temperature was lower than the technological one, as well as the effect of the modification which is inefficient. The zone exhibits separations of lamellar graphite of semiarched shape and nest-shaped graphite separations. One witnesses the occurrence of only very small modified lamellar graphite (glm) separations. The second sample, Figure 4, confirms the cause of the material defect. The degenerate shape of primary graphite can be remarked. It may occur in the structure of the pig iron of the second fusion only if the loading of the elaboration furnace was made with furnace raw pig iron, but not of high purity; the primary, hereditary pig iron separates following the incomplete dissolution of the graphite from the first-fusion pig iron-furnace raw iron pig, at the melting of the metallic charge; the seeds or grains of primary hereditary graphite may lead to the increase of primary hereditary graphite separations, at the solidification of the second-fusion grey pig iron; we witness a directing of carbon atoms from the melt toward theses grains with a distribution towards the limit of the eutectic cell very close to the typical shape of the interdendritic graphite.

The microstructure in Figure 5 indicates a correct separation of secondary graphitisation, with around $50 \mu \mathrm{m}$-long graphite lamellas, but not with rounded points, as well as a rather inappropriate length, considering the part mass (11t), which at a slow cooling would have led to the enlargement of the graphite lamellas to around $100-150 \mu \mathrm{m}$. They are shapes of separations of modified lamellar graphite. In Figure 6 we remark that the metallic basic mass is pearlite.

3.2. Macro- and Microstructural Analysis of the Part in Zone $A$. In Figure 7 the macroaspect is appropriate, typical for pearlitic grey iron pig with a granulation specific to the studied make of pig iron.

The sample in Figure 8 is without reactive attack and allows the observation of the graphite distribution, which is lamellar, with appropriate length, but with smaller widths and without rounded points (it produces the effect of growth in the basic metallic mass). This leads to the conclusion that we need a better modification in the casting ladle, with FeSi75, and to the setting of an appropriate casting temperature. The following areas examined in Figure 8 (microstructure in zone A) and Figure 9 (microstructure in zone A) validate the conclusions. The analysis with reactives highlights a pearlitic base metallic mass, Figure 9.

\subsection{Macro- and Microstructural Analysis of the Part in Zone $B$. In Figure 10 the macro aspect is appropriate, typical for the pearlitic grey pig iron with a granulation specific to the studied make of pig iron. \\ In Figure 11 we remark the size of the graphite lamellas, smaller than in the pig iron from the other runner basin,}




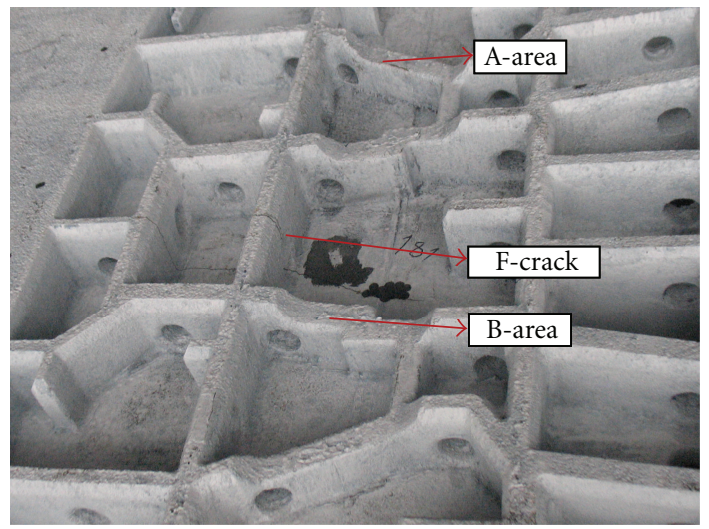

Figure 1: Areas where the metallographic samples were extracted (A, B) and crack in the part (F).

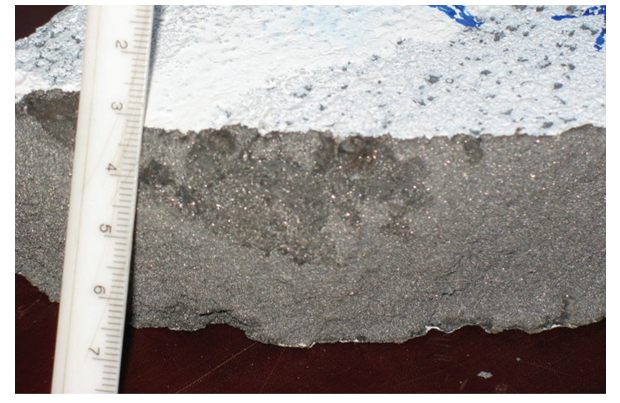

FIGURE 2: Zone F macroaspect of the sample in the cracked area.

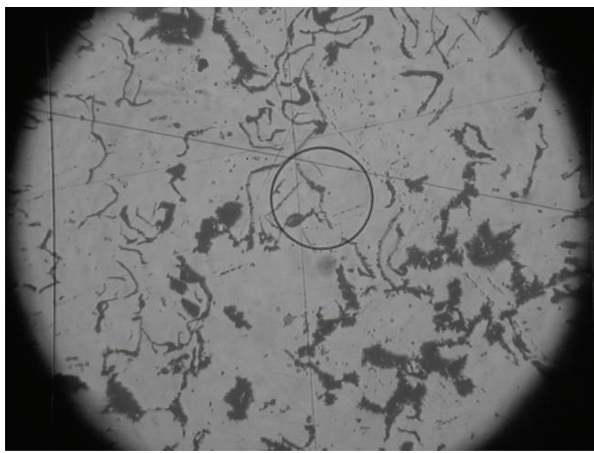

Figure 3: Microstructure in zone F 100x.

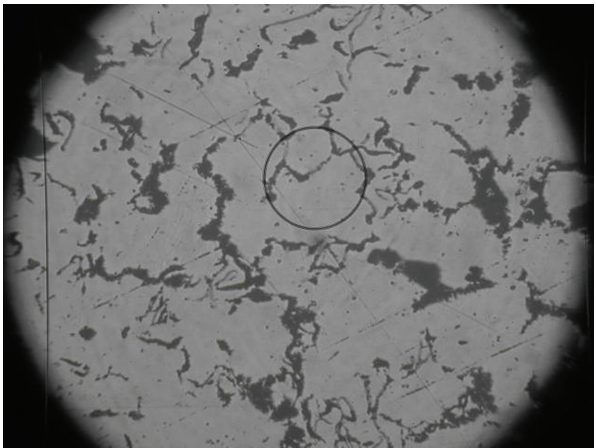

FIgURE 4: Microstructure in zone F 100x.

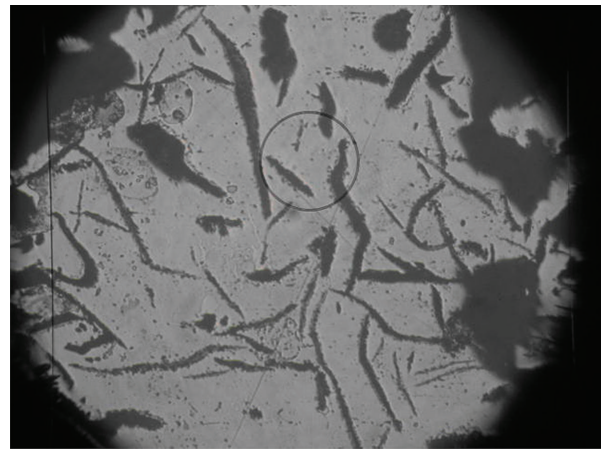

FIgURe 5: Microstructure in zone F 100x.

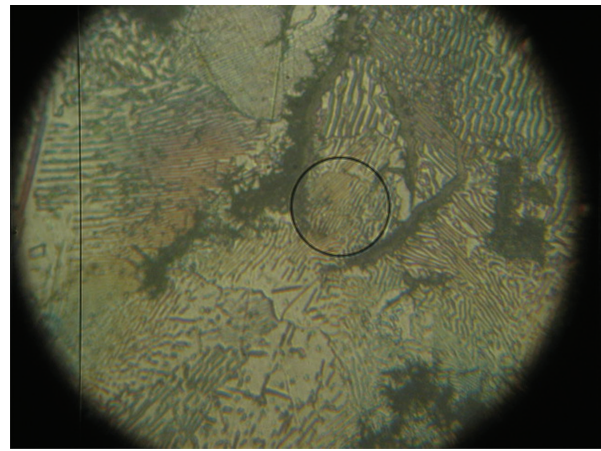

FIGURE 6: Microstructure in zone F 500x.

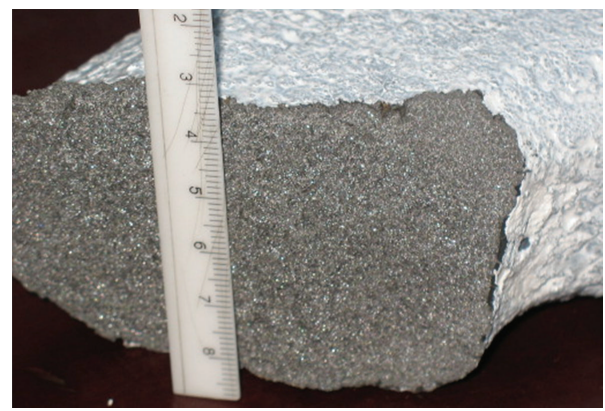

FIGURE 7: Macroaspect of the sample in zone A. 


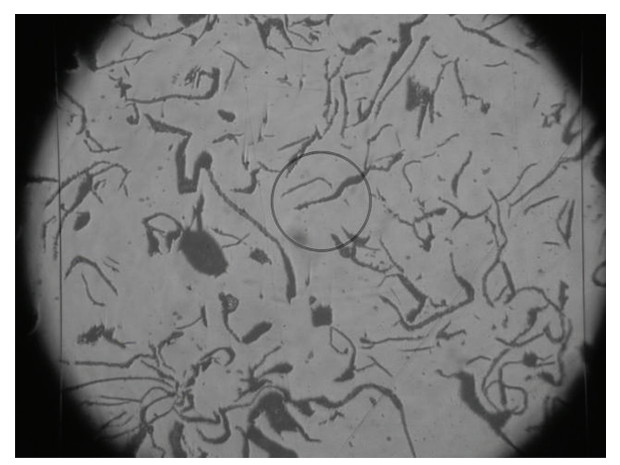

FIgURE 8: Microstructure in zone A 100x.

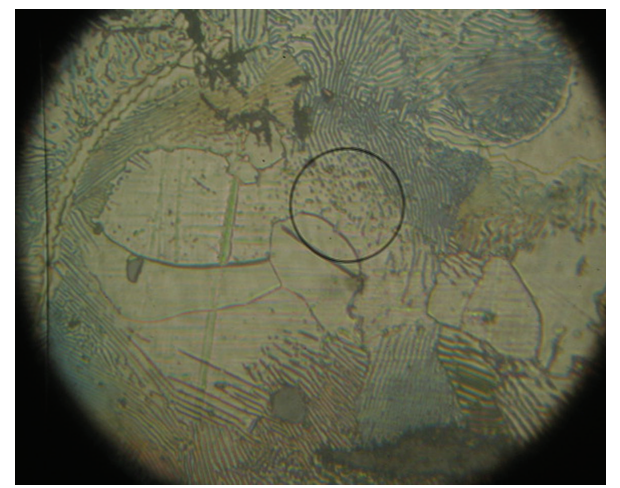

Figure 9: Microstructure in zone A 500x.

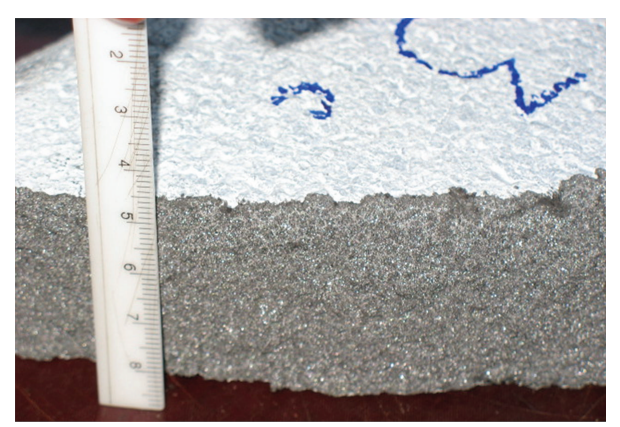

FIgURE 10: Macroaspect of the sample in zone B.

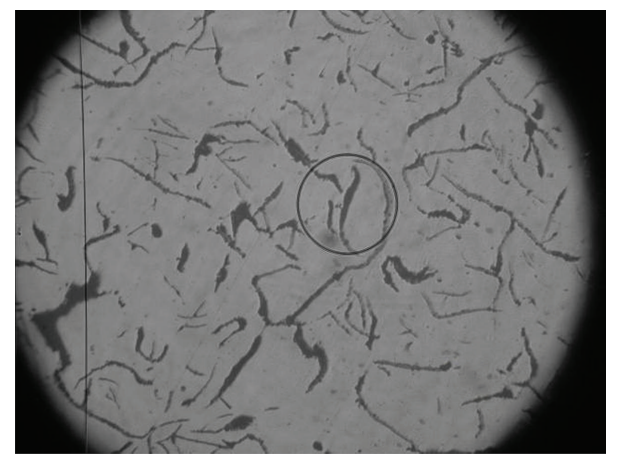

FIGURE 11: Microstructure in zone B 100x.

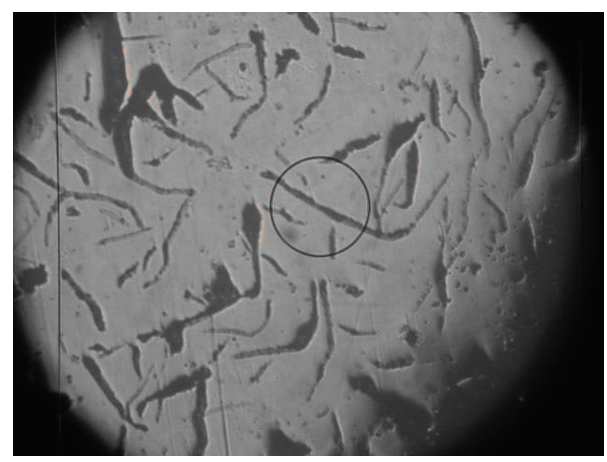

Figure 12: Microstructure in zone B 100x.

possibly more weakly modified and colder cast. The microanalysis in the adjacent area, Figure 12, exhibits a better microstructure than the previous one, not by much, but enough to draw the conclusion of a weaker thermal-chemical homogenisation, at sprue cup no. 1 . The microanalysis with reactives shows a pearlitic base metallic mass, with areas of binary phosphorus eutectic.

\section{Conclusions}

From the macroanalysis of the part we remarked the deficiencies of design, moulding and elaboration which trigger the occurrence of the defect:

(i) T-joinings between the walls of the part with great differences in widths (ribs and base plates);

(ii) the crack is caused by a braked contraction triggered by the ribs-walls and the use of certain coresthe mixture mould which does not enable the free contraction of the part (noncompressible mouldingcoring mixtures);

(iii) a high amount of internal strains was accumulated on the part base plate as a result of the braked contraction at solidification and cooling;

(iv) it is possible that the crack started from some triggers - internal casting defects: nonmetallic inclusions or air bubbles and even the shape of the phosphorous eutectic, which may constitute strain concentrators; we do not analyse the surface defects (there are many) which negatively influence the mechanic characteristic to a great extent;

(v) the crack does not start and does not pass through the orifices of the ribs because (fact proved experimentally) the holes are limits (obstacles) for the fissures propagation;

(vi) the execution of the model is inappropriate because at the walls joints one has not manufactured adequate junction rays which would have allowed the partial elimination of the formation of corner cavities, taking into account also the fact that having joined walls of different width stressed the tendency of formation of thermal knots, corner cavities, and 
axial microcavities (see the simulation, especially the temperature variation during filling);

(vii) the middle area, that is, the zone where the fissure occurs and at the same time the merging area of the two jets (flowing currents) of the liquid pig iron exhibits nonmetallic inclusions oxides, sulphides, and small gaseous inclusions-air bubbles_-which may constitute fissure triggers under conditions of very high internal strains generated by a brakes contraction during solidification and cooling;

(viii) there occur areas of primary graphitisation in insufficiently developed eutectic cells, due to the low casting temperature $\left(1220^{\circ} \mathrm{C}\right)$, and to a cooling area with accelerated rate;

(ix) the inefficient modification of the pig iron and the exceeding of the delay between modification and casting, over 15 minutes;

(x) due to the fact that the part casting was made with two sprue cups, we encounter two liquid fronts of different temperatures (of which one liquid front has the temperature below the technological casting level), as well as the differences in the chemical composition.

\section{Analysis of the Possibility of Defect Prediction Using the Simulation of Casting and Solidification of the ENGJL 200 Pig Iron}

All software for simulating alloys casting and solidification has 4 main modules, that is, $[2,5]$ :

(i) database, where the materials are found with their physical and chemical properties;

(ii) preprocessor, where we introduce the parameters necessary to the simulation, that is, type of alloy, properties of the casting mould, alloy temperature, mould temperature, coefficients of heat transfer, specific coefficients which may determine defects and mechanical properties;

(iii) solver;

(iv) postprocessor, which presents the results of the simulation based on the data introduced by the operator.

It is important to point out that the assessment of the part cast through classical methods and then subjected to simulation results in obtaining certain data which help a lot the user of the software to make the best predictions. As shown in point 2 , the second section of the study refers to the simulation of the part casting under conditions identical with those in which the analysed part was cast. The casting was done in polystyrene mould with furanic resin cores. The casting temperature was of $1250^{\circ} \mathrm{C}$, then alloy is EN GJL 200 grey pig iron, the chemical analysis shown in Table 1 . The casting of the part was done with two sprue cups, technology presented in Figure 13, where in red we see the position of the two runner basins, and of the two mould feeders. The casting with two basins was chosen as the mass of the part together with the casting network is $12,000 \mathrm{~kg}$.

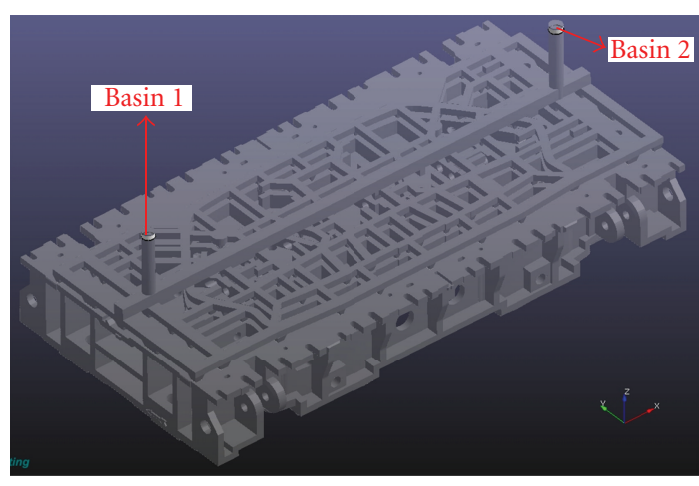

Figure 13: Presentation of the casting model with two basins.

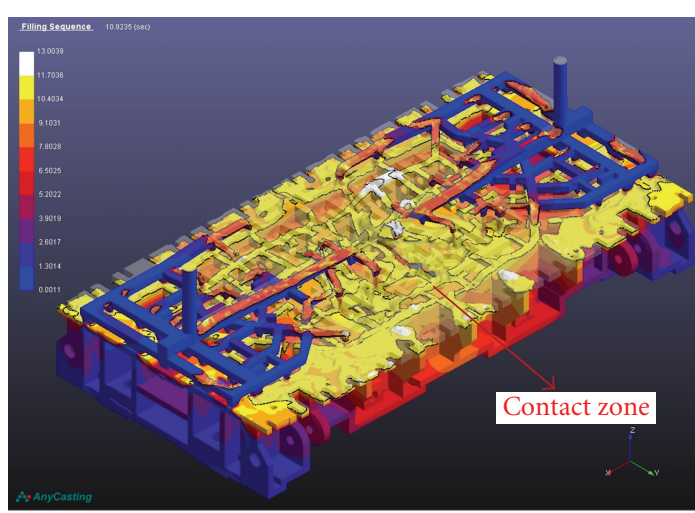

Figure 14: Convergence area of the two front.

The casting of the part was made with two basins, we encounter two liquid fronts with different temperatures (of which one liquid front with the temperature below the technological casting level), as well as differences in the chemical composition.

In the case of casting in polystyrene moulds the feeding is made from the upper section through a feeding network resulting in the downward casting towards the base of the casting mould [6]. Consequently the filling of the mould is made from base to the upper part. Figure 14 shows the simulation of the pig iron filling from two sprue cups, using the filling sequence criterion $[1,6]$. As remarked, the two liquid fronts converge in the middle area of the part, where the casting defect appears. By analysing the process, according to the colour code displayed in the left side, we find that the most rapid filling takes place in the feeding network at 0.0011-second time, in the area indicated with the red arrow the liquid from basin 1 meets the liquid from basin 2 after around 11,7036 seconds. Moreover, we remark in the same area a turbulence specific to the encounter of two liquid jets. Figure 14 does not show all the filling sequences, we selected those which represent the most accurately the moment of interest.

Another criterion used and presented in Figure 15 is the retained melt volume, measured in $\mathrm{cm}^{3}$ of volume of liquid metal retained in certain areas and is used in order to visualise the zone where liquid volumes remain, that is, 


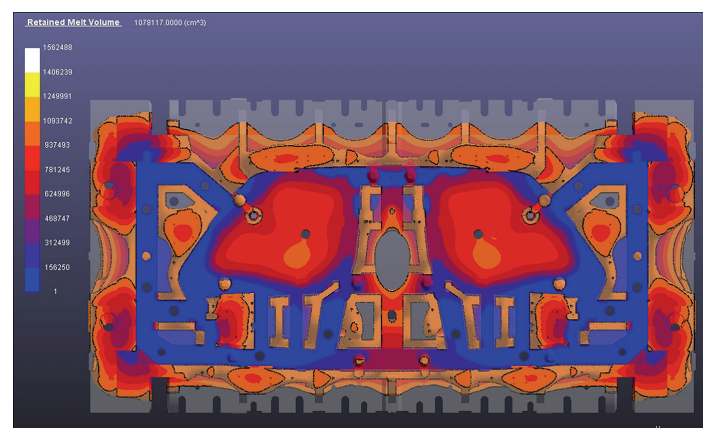

FIGURE 15: The retained melt volume criterion.

which zone solidifies more slowly than the others. Another interpretation refers to the fact that it shows the areas that retain the largest quality of liquid metal. In the median area, where the two fronts unite, the volume of liquid metal ranges between 312,499 and $1,093,742 \mathrm{~cm}^{3}$ at a total volume of $10,791,170,000 \mathrm{~cm}^{3}$. One remarks the separation of two fronts of liquid that will contract later on from the median area, which cross the thermal area from the solidified phase, where the mechanic strength is reduced and the local wall width also small. This fact leads to the predisposition to cracking of the part as a result of the existence of uncompensated mechanical strains $[3,5]$.

This situation is favoured both by the metallographic microstructure, made of primary graphite separations, within insufficiently developed lamellas, as well as by the high rate of passage through the solidification range. Moreover, the very median zone, as it has the less ribs and is by $30 \mathrm{~mm}$ thinner compared to the neighbouring areas, does not enable a sufficient mechanical consolidation at the passage through the solidification range. This leads us to the assumption of the existence of a prefissured state, even from the solidification period [7].

In this state the internal tensions generated by the inappropriate design of the model, the lack of chemical and thermal homogeneity may pass unobserved at the extraction from the mould, during painting (grounding), and the defect risks to be amplified during later manipulation or during transport.

So in Figure 16 we see in the preprocessor another relevant criterion, that is, the temperature variation during the solidification of the casting mould. The solid of the cast part subjected to simulation was made after measurements performed on the cast part. The solid thus realised was introduced in preprocessor and we applied the condition of real casting parameters. Thus we find design errors, that is, the left and right ribs are $50 \mathrm{~mm}$ thick and the middle one is $25 \mathrm{~mm}$ thick. Consequently, the middle area cools more rapidly than the side ones, which cool more slowly. Moreover, the distortions generated by the differentiation of solidification in time and constrained by the rigidity of the moulding mixture, generates local, uncompensated tensions [8]. The criterion "temperature variation during the alloy mould filling" show that the filling time of the mould is of 373,537 seconds, that is 6,21 minutes. We may deduce very easily also the filling rate. At this value filling is $100 \%$

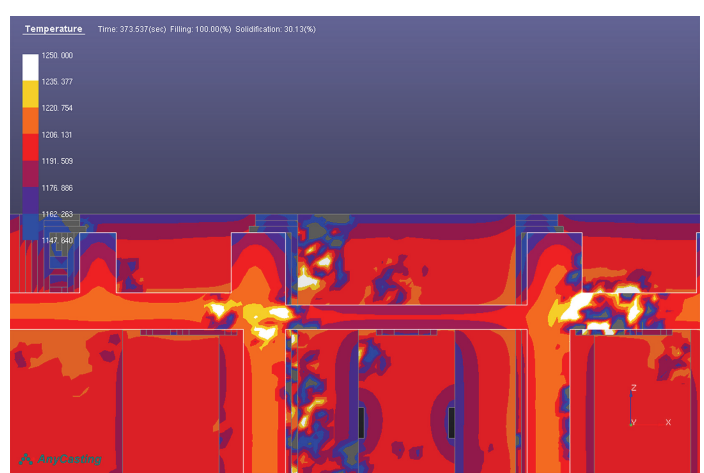

Figure 16: Temperature variation during alloy solidification. Section in the defect zone.

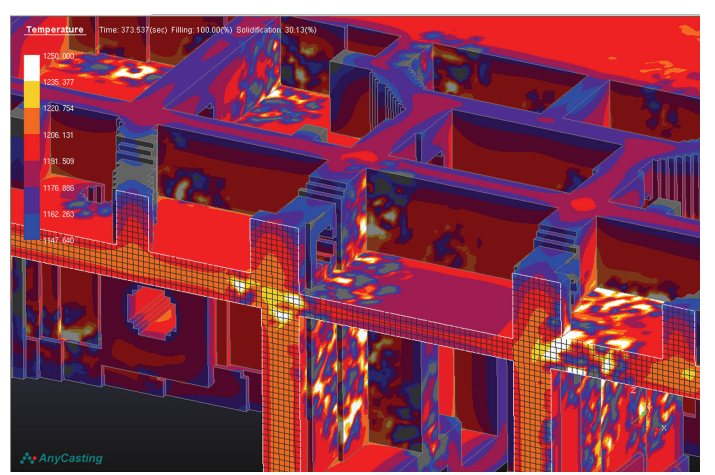

Figure 17: Temperature variation during alloy solidification. Meshed section in the defect area.

and we remark a $30 \%$ solidification, which explains that during the part filling the solidification processes also start. By analysing the criterion according to the colours code displayed in the left side, Figures 16 and 17, the solidification starts from the lateral sides of the part towards the middle, the temperature ranging between $1147^{\circ} \mathrm{C}$ (blue-coloured areas) and $1250^{\circ} \mathrm{C}$ (white-coloured areas). The presence of $1250^{\circ} \mathrm{C}$ temperatures especially in the joining areas between ribs points out the presence of heat knots in the part. Starting from this fact, simulation shows that fissures are likely to occur starting from the "+-" or "T-" shaped joints of the thick walls (ribs), with the same wall thickness or with different thicknesses, and even in the middle areas of the thick walls which solidify among the last areas; the thermal knot occurs in joints [9].

Grosser seeds or grains are formed preponderantly in the ribs situated towards the central part of the part where the solidification-cooling rate and the aforementioned joints in the walls (T-shaped heat knot) and where it is lower than in the rest of the part; the higher the cooling rate, the smaller the sizes of grains (but we must be careful, as a very high cooling rate risks to lead to the separation of free cementite).

Figure 17 shows a section and the meshed perspective, which allows a more detailed visualisation of the area of interest. By comparing the colours of certain zones of the part with the colour code in the left side, we can study the solidification and cooling of the part, and we remark that 
the solidification front starts from the extreme sections of the part and especially from the sections in contact with the atmosphere. The area which solidifies the most rapidly is that with the thinnest wall [10].

One proceeded to the nondestructive control of the part, to the identification and location of other hidden casting defects. One measured the inductivity of different areas of the part, and found a predisposition to defects in the median area, where the measured items exhibited higher values.

5.1. Conclusions. The simulation software cannot exhibit aspects related to the nonobservance of the technology of pig iron elaboration. By introducing the parameters of the cast part in the software preprocessor and the display of the results in the postprocessor we get an image very close to reality:

(i) simulation highlights the convergence area of the two liquid fronts, zone which, by measurements, coincides with the position of the defect in the cast part;

(ii) it presents by the analysis of the solid all the design deficiencies, that is, the "+" or " $T$ " joints of the thick walls, zones solidify among the last;

(iii) the presence of $1250^{\circ} \mathrm{C}$ temperatures especially in the joining areas between ribs highlight the presence of heat knots in the part.

\section{Final Conclusions}

Following the analysis of the simulation results and of conclusions in point 4 and point 5.1 some proposals resulted in view of enhancement the casting technology:

(i) it is necessary to modify the part execution design, by increasing the wall thickness in the defect occurrence area;

(ii) in order to have a high quality of the cast iron, it is necessary to correctly apply the modification technology, and the time between modification and casting must be observed;

(iii) casting the part at a temperature which should take into account the heat losses caused by the transfer of the locked form the furnace in the ladle or sprue cup. The recommended temperature in this situation is of $1350^{\circ} \mathrm{C}$;

(iv) due to the fact that the part casting was performed with two runner basins, two liquid fronts of different temperatures converge; consequently it is required that the temperature of the two liquid fronts be equal, as well as their chemical composition;

(v) a series of anomalies found may be avoided by modifying the moulding-casting technology and the use of compressible moulding mixture (preferably from moulding mixtures bound with classic inorganic binders) if we are interested in the part compactness and metallographic structure; (vi) technological control of heat knots may be done by building some vent holes at moulding-casting, placed on the wall joints;

(vii) it is necessary to correct the moulding-casting technology, by correcting the construction of the model, with the realisation of junction rays on the model and manufacturing air vents made of the same material of the model, alterations which also lead to the modification of the mould execution;

(viii) it is necessary to build a new polystyrene model;

(ix) it is required to manufacture a new part with the updated model.

By comparing the simulation results with the practical ones and vice-versa, the application of simulations of some cast parts provide the user with a very accurate instrument for the anticipation of defects and their apparition and at the same time leads to the building of a very useful database.

\section{References}

[1] SR UNE EN, 1560:2011 Founding-designation system for cast iron-materials symbols and material numbers, 2011.

[2] AnyCasting, DataBase, Advanced Casting Simulation Software, version 3.10, 2009.

[3] M. Skarbinski, Construcţia pieselor turnate şi proiectarea formelor (traducere din limba polonă), Technical Editions, Bucharest, Romania, 1967.

[4] C. Ştefănescu, C. Cosneanu, and V. Dumitrescu, Îndrumătorul proiectantului de tehnologii în turnătorii, vol. 1, Technical Editions, Bucharest, Romania, 1985.

[5] E. Piwowarsky, Fonte de inalta calitate, Technical Editions, Bucharest, Romania, 1967.

[6] AnyCasting, Advanced Casting Simulation Software, version 3.10, 2009.

[7] C. Marta, Aplicatii in AnyCasting, Efimie Murgu Editions, 2011.

[8] B. Liu, H. Shen, and W. Li, "Progress in numerical simulation of solidification process of shaped casting," Journal of Materials Science and Technology, vol. 11, pp. 313-322, 1995.

[9] I. Ciobanu, M. Chisamera, S. I. Munteanu et al., "Researches about the determination of the thermal conductivity coefficient for silica sand moulds used in Romanian foundries," Key Engineering Materials, vol. 457, pp. 312-317, 2011.

[10] D. M. Stefanescu, Science and Engineering of Casting Solidification, Kluver Academic, Plenum, New York, NY, USA, 2002. 

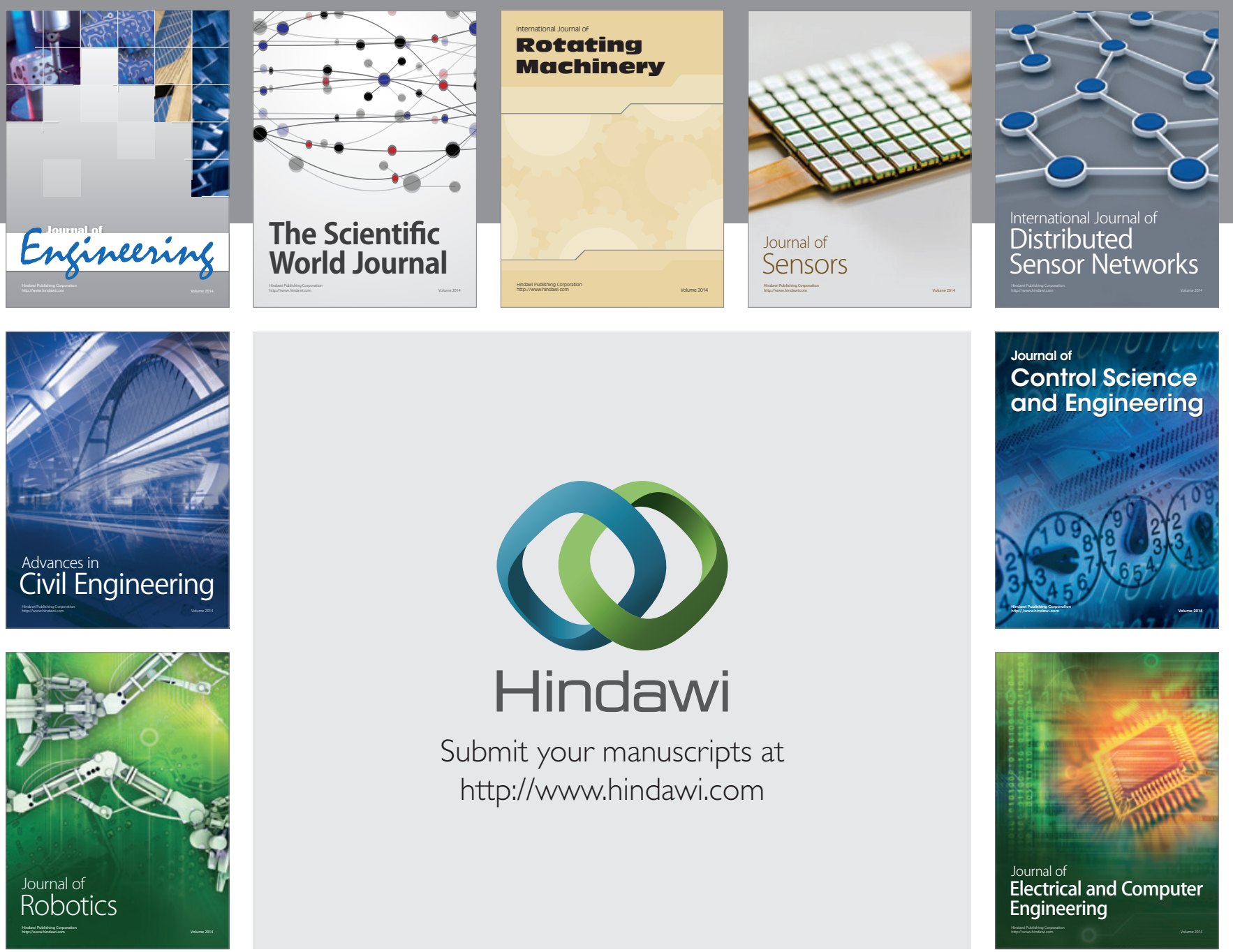

Submit your manuscripts at

http://www.hindawi.com
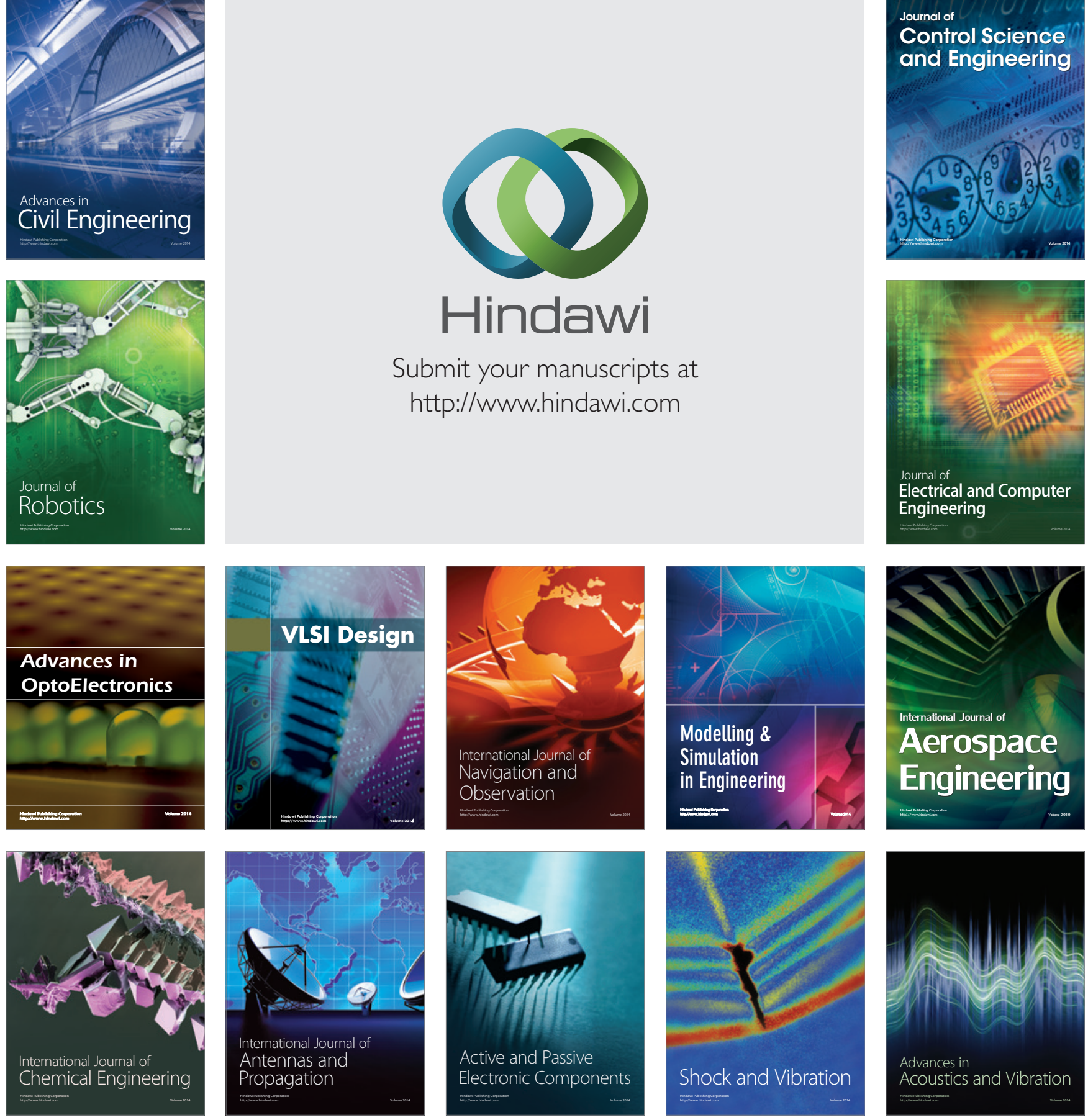